\title{
Meningitis aséptica en pacientes con parotiditis viral durante un brote epidémico
}

\author{
Alberto Fica ${ }^{1,2}$, María C. Díaz ${ }^{1,2}$, Constanza Aguilar ${ }^{3}$ y Juan C. Velásquez
}

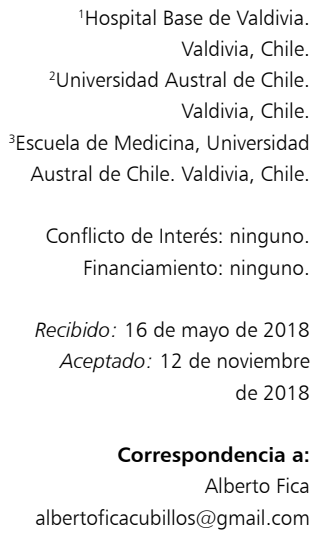

Hospital Base de Valdivia.

Valdivia, Chile.

¿Universidad Austral de Chile.

Valdivia, Chile.

${ }^{3}$ Escuela de Medicina, Universidad Austral de Chile. Valdivia, Chile.

Conflicto de Interés: ninguno. Financiamiento: ninguno.

Recibido: 16 de mayo de 2018 Aceptado: 12 de noviembre de 2018

Correspondencia a: Alberto Fica albertoficacubillos@gmail.com

\section{Aseptic meningitis associated to mumps during an epidemic outbreak}

We report two cases of acute aseptic meningitis associated to mumps in middle-aged women, one pregnant. Both presented shortly after parotid gland enlargement. Neurological complications were suspected by headache, fever and meningeal signs and confirmed by CSF findings (mononuclear predominant pleocytosis) with negative results for alternative causes. Mumps were confirmed by positive IgM and IgG serology. Both patients were discharged with a favorable evolution and complete disappearance of symptoms. Cases were concurrent with a regional mumps outbreak. Conclusions: Aseptic meningitis is a rare mumps-associated neurological complication. Its diagnostic can be achieved by precedent parotid enlargement, mononuclear pleocytosis in the CSF and positive IgM and IgG serology or viral detection by PCR in urine or salivary samples. This complication would be more probably observed during mumps outbreaks.

Keywords: Mumps; aseptic meningitis; disease outbreak; polymerase chain reaction; serology.

Palabras clave: Parotiditis; meningitis aseptic; brote epidémico; reacción de polimerasa en cadena; serología.

\section{Introducción}

L a parotiditis viral es una enfermedad aguda que compromete una o ambas glándulas salivales y cuya incidencia global en Chile descendió dramáticamente en los años 90, luego de la introducción de la vacuna. Esta enfermedad se asocia a algunas complicaciones como orquitis post-puberal, ooforitis, sordera, artritis, pancreatitis, tiroiditis, meningitis o encefalitis y rara vez puede causar la muerte. La vacuna no sólo disminuye la frecuencia de la enfermedad, sino que también las hospitalizaciones y las complicaciones asociadas ${ }^{1}$.

En los últimos años se ha observado una reemergencia epidemiológica de la parotiditis viral en diferentes países y que afecta principalmente a adolescentes y adultos jóvenes $^{1-6}$. En Chile, también se ha observado un brote epidémico desde el año 2015 que afecta predominantemente a niños, adolescentes y adultos jóvenes, aunque el rango etario también incluye adultos mayores ${ }^{7}$.

Debido a la baja frecuencia de esta enfermedad en las últimas décadas en Chile, con no más de cinco casos por 100.000 habitantes, equivalente a menos de 800 casos anuales, la experiencia clínica de sus complicaciones neurológicas ha sido remota o inexistente para varias generaciones médicas en nuestro país.

Recientemente, hemos observado dos casos de parotiditis viral asociados a meningitis en la región de Los Ríos que es de interés comunicar para alertar a los equipos de salud de esta complicación. Estos casos aparecieron du- rante un brote regional de esta enfermedad, cuyos datos se incluyen para contextualizar este tipo de complicaciones.

\section{Caso clínico 1}

Mujer de 34 años, con hipotiroidismo en control adecuado y funcionaria de un vacunatorio de la ciudad. En septiembre de 2017, al octavo día de evolución de un aumento parotídeo bilateral, presentó cefalea holocránea y fiebre hasta $39^{\circ} \mathrm{C}$. En la consulta inicial se indicó tratamiento sintomático. Volvió a consultar a las $48 \mathrm{~h}$ por persistencia de los síntomas, agregándose vómitos y vértigo. Al examen físico se pesquisaron signos meníngeos esbozados por lo que se sospechó una meningitis. Al examen inicial la paciente se encontraba en buenas condiciones generales sin compromiso sensorial, con temperatura axilar de $37,4^{\circ} \mathrm{C}$, hemodinamia estable, con aumento de volumen parotídeo bilateral y leve dismetría, sin otros hallazgos neurológicos. El estudio del LCR mostró una proteinorraquia leve (Tabla 1) y pleocitosis de predominio mononuclear. No se detectaron agentes específicos en el estudio complementario del LCR con RPC múltiplex para virus herpes simplex 1 y 2 , virus herpes 6 y 7, virus varicela zoster, citomegalovirus, virus de Epstein Barr, enterovirus, parechovirus, parvovirus B19 y adenovirus. El hemograma y análisis bioquímico general era normal, excepto por un aumento de los niveles de amilasemia. El estudio serológico con IgG e IgM para 


\begin{tabular}{|c|c|c|}
\hline & Caso 1 & Caso 2 \\
\hline Mes, año & Septiembre, 2017 & Abril, 2018 \\
\hline Sexo, Edad & Femenino, 34 años & Femenino, 32 años \\
\hline Morbilidad asociada & Hipotiroidismo & Embarazo 33 semanas \\
\hline Manifestación clínica & Meningitis (cefalea, fiebre, vómitos, vértigo, signos meníngeos) & Meningitis (cefalea, fiebre, signos meníngeos) \\
\hline Relación temporal con parotiditis & Ocho días & Seis días \\
\hline Hallazgos estudio citoquímico del LCR & $\begin{array}{l}\text { Glucorraquia } 54 \mathrm{mg} / \mathrm{dL} \\
\text { Proteinorraquia } 87 \mathrm{mg} / \mathrm{dL} \\
\text { Leucocitos } 280 \text { céls } / \mathrm{mm}^{3} \\
\text { Mononucleares } 99 \%\end{array}$ & $\begin{array}{l}\text { Glucorraquia } 34 \mathrm{mg} / \mathrm{dL} \\
\text { Proteinorraquia } 44 \mathrm{mg} / \mathrm{dL} \\
\text { Leucocitos } 95 \text { céls } / \mathrm{mm}^{3} \\
\text { Mononucleares } 98 \%\end{array}$ \\
\hline Amilasemia & $490 \mathrm{U} / \mathrm{L}$ (normal < $100 \mathrm{U} / \mathrm{L}$ ) & $172 \mathrm{U} / \mathrm{L}$ (normal < $100 \mathrm{U} / \mathrm{L}$ ) \\
\hline Estudio otros agentes & $\begin{array}{l}\text { Negativo por panel molecular para } 11 \text { agentes virales en LCR } \\
\text { Serología VIH no reactiva } \\
\text { VDRL no reactivo } \\
\text { Hemocultivos negativos }\end{array}$ & $\begin{array}{l}\text { Negativo por panel molecular para } 11 \text { agentes virales en LCR } \\
\text { Serología VIH no reactiva } \\
\text { VDRL no reactiva } \\
\text { Hemocultivos negativos }\end{array}$ \\
\hline Serología IgG/lgM virus parotídeo & Positiva/Positiva & Positiva/Positiva \\
\hline Evolución & Favorable, sin secuelas & Febril por 24 h, cefalea por 5 días \\
\hline
\end{tabular}

virus parotídeo resultó positivo para ambos anticuerpos. Los hemocultivos y cultivo de LCR no demostraron crecimiento bacteriano. La tomografía computada cerebral no reveló lesiones estructurales. Por el antecedente de hipotiroidismo se solicitaron títulos de anticuerpos antinucleares los que fueron inicialmente positivos en valores $1 / 160$, con negatividad para anticuerpos anti Ro y anti La, propios del síndrome de Sjögren y negatividad también para anticuerpos anti-ADN. Asimismo, las cifras de complemento sanguíneo $\mathrm{C} 3$ y C4 fueron normales, al igual que los valores de factor reumatoideo y hormonas tiroideas. Tuvo una evolución favorable, sin secuelas. A pesar de trabajar en un vacunatorio, no recordó haber tenido contacto con pacientes con parotiditis y tampoco de las vacunas recibidas en su infancia. Los títulos de anticuerpos antinucleares se redujeron, posteriormente, a valores $1 / 40$, a los dos meses de seguimiento.

\section{Caso clínico 2}

Mujer de 32 años, con un embarazo de 33 semanas, consultó en abril de 2018 por dos días de cefalea intensa holocránea de inicio brusco, acompañada de fiebre, fotofobia, anorexia y malestar general. Al interrogatorio dirigido refirió un cuadro de parotiditis bilateral desde hacía una semana e inicialmente diarrea autolimitada. Al examen físico la paciente se encontraba lúcida y orientada con signos meníngeos presentes, sin compromiso hemodinámico, ni lesiones cutáneas. Se pesquisó un leve aumento de volumen parotídeo indoloro. No tenía recuerdo de haber tenido contacto con personas con parotiditis ni las vacunas recibidas en su infancia. Tenía un hemograma normal y un leve aumento de los niveles de amilasemia (172 U/L) (Tabla 1). El estudio del LCR tenía proteínas en rango normal, hipoglucorraquia (34 mg/dL), pleocitosis de 95 céls $/ \mu \mathrm{L}$ de predominio mononuclear $98 \%$ (Tabla 1 ). El estudio molecular para 11 agentes virales en el LCR fue negativo, al igual que el cultivo y los hemocultivos, por lo que se suspendió el tratamiento empírico inicial con ceftriaxona a las $24 \mathrm{~h}$ de su inicio. Luego de las primeras $24 \mathrm{~h}$, evoluciona en forma favorable, con desaparición de la fiebre, disminución notoria de la cefalea y de los signos meníngeos. Se dio de alta a los tres días, con control telefónico que confirmó la ausencia de síntomas. Posteriormente, se recibió el informe de serología IgG e IgM positiva para virus parotídeo.

\section{Análisis epidemiológico}

Gracias a los datos obtenidos de las notificaciones obligatorias para esta enfermedad en los últimos años y los datos poblacionales en la Región de Los Ríos, se pudo 


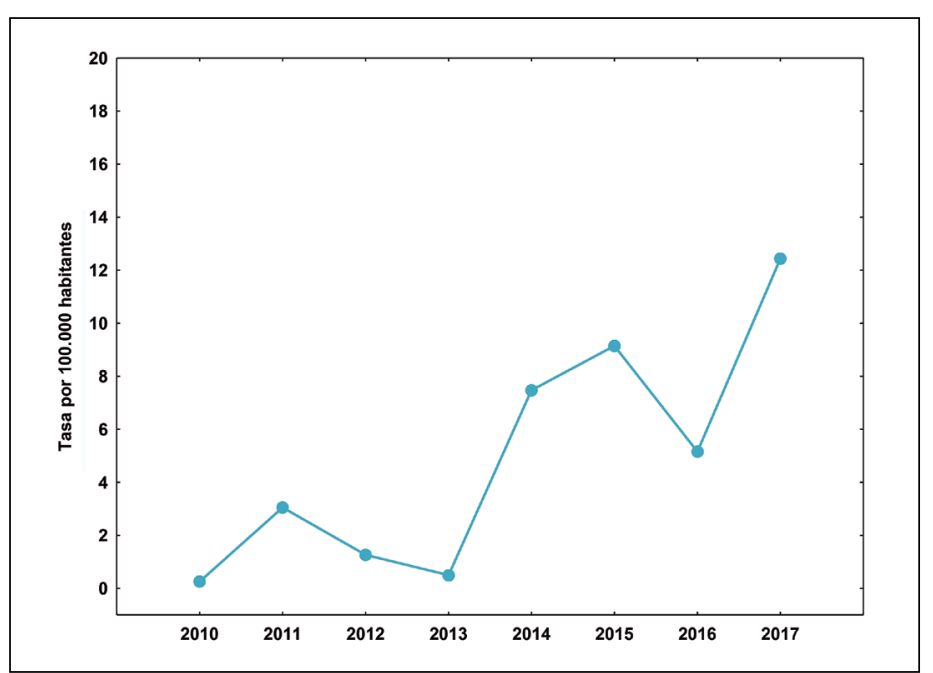

Figura 1. Tasa de incidencia de parotiditis viral en la Región de Los Ríos, 2010-2017. Datos obtenidos desde la Unidad de Epidemiología del Hospital Base de Valdivia.

analizar la distribución temporal y por grupos específicos de edad. Esta información se obtuvo desde la Unidad de Epidemiología del Hospital Base de Valdivia.

La tasa de incidencia de parotiditis viral reportada en la región ha aumentado desde el año 2014 con un valor máximo registrado para el 2017, año de presentación del primer caso presentado (Figura 1). La tasa específica por grupos etarios (Figura 2), revela que todos ellos están comprometidos aunque con una mayor tasa de incidencia en la primera década de la vida, secundada por el grupo adolescente. Los dos casos aquí descritos corresponden al grupo de 30-39 años de edad. La distribución mensual desde 2010 a abril de 2018, indica la presencia de casos durante todo el año, un predominio de casos en abril y ausencia de estacionalidad clara (Figura 3). Tomando el total de los casos de parotiditis viral notificados el año 2017 en la Región de Los Ríos $(\mathrm{n}=51)$ y los casos de meningitis reportados por esta causa (un solo caso) se pudo estimar una tasa de $2 \%$ para esta complicación, para el año comentado.

\section{Discusión}

La parotiditis viral es una enfermedad inmunoprevenible que se redujo notoriamente en Chile en los años 90 al incorporar dos dosis de una vacuna atenuada en el Programa Nacional de Inmunizaciones, al primer año de vida y luego a los seis años de edad. El objetivo de esta estrategia es disminuir la morbilidad y complicaciones asociadas a este agente. En la era preinmunización, esta enfermedad afectaba principalmente a la población infantil. Gracias a la vacuna y a las altas tasas de cobertura, se ha observado una reducción notable en la frecuencia de casos y sus complicaciones. Sin embargo, luego de varias décadas, los países que han incorporado esta vacuna han observado casos esporádicos y brotes en adolescentes y adultos jóvenes, probablemente por la pérdida del

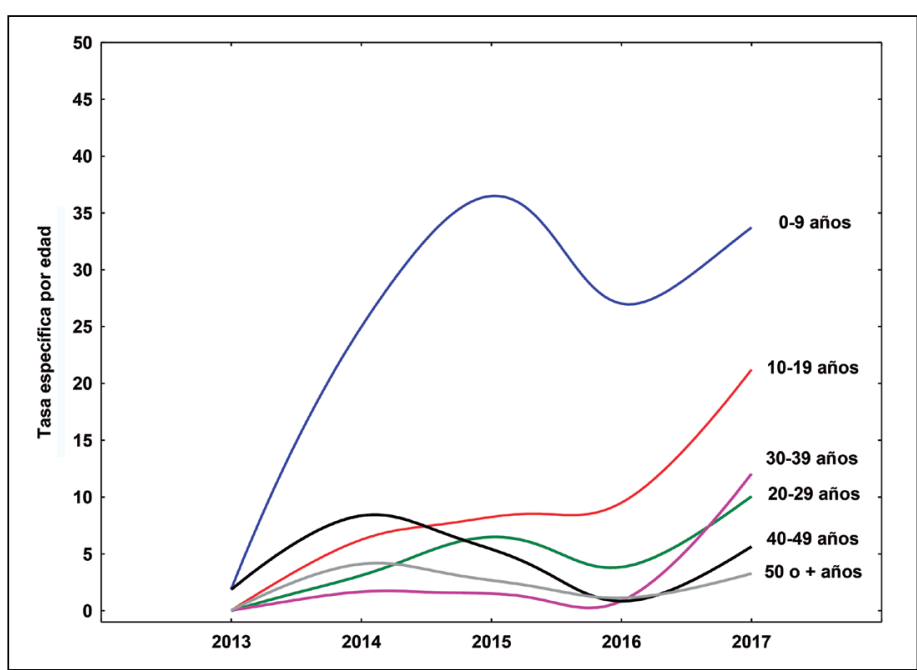

Figura 2. Tasas específicas por edad de parotiditis viral en la Región de Los Ríos en los últimos 5 años. Las curvas fueron obtenidas por el método de los mínimos cuadrados para facilitar la lectura de las tendencias.

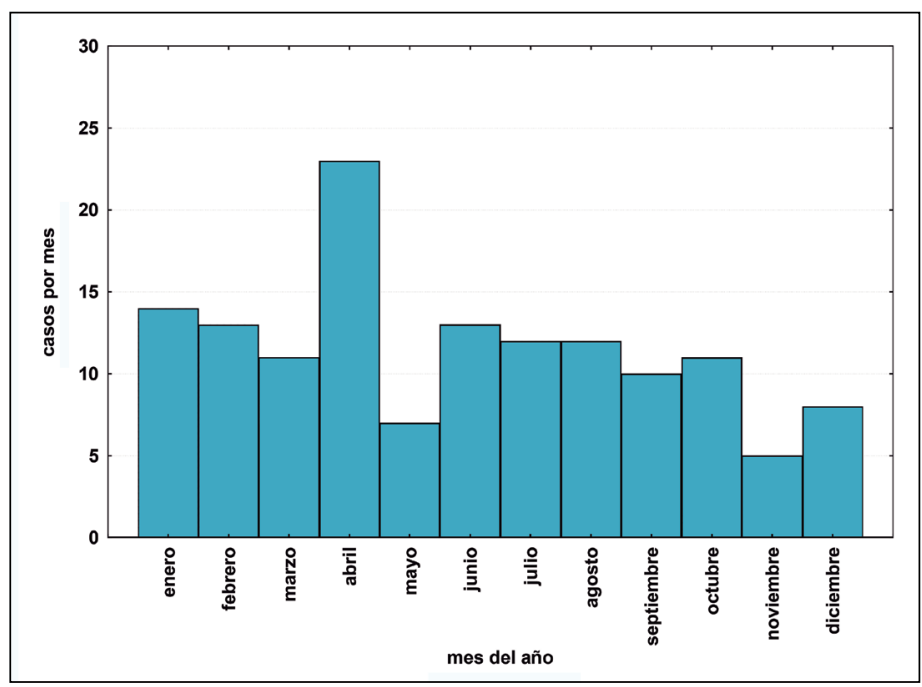

Figura 3. Distribución de casos de parotiditis viral según mes de aparición de síntomas, Región de los Ríos, 2010 a abril de 2018.

refuerzo inmunitario que significaba la exposición a un gran número de infectados en la población y la reducción progresiva de la efectividad protectora de la vacuna en el tiempo $0^{2-6,8}$. Estudios epidemiológicos han podido determinar que el riesgo de parotiditis aumenta nueve veces en los expuestos cuando han transcurrido más de 13 años de la última dosis de la vacuna ${ }^{6}$. De esta manera, la vacuna ha sido beneficiosa, pero ha generado un desplazamiento epidemiológico de la enfermedad y la ocurrencia de brotes en la comunidad.

Datos observaciones muestran que la tasa de cualquier complicación en personas no vacunadas puede llegar a $25 \%$ y se reduce a menos de $7 \%$ con una o dos dosis de vacuna y que las hospitalizaciones 
también disminuyen de $30 \%$ a menos de $10 \%$ con la vacuna. La frecuencia de orquitis baja en cifras similares y los casos de meningitis, desde $4 \%$ en no vacunados a valores cercanos a $1 \%$ en receptores de una o dos dosis de vacuna ${ }^{9}$. Pudimos calcular la tasa de meningitis para el año 2017 en nuestra región y la cifra obtenida se ubica en el rango comentado ( $2 \%)$. La encefalitis y pancreatitis, siendo infrecuentes en no vacunados $(<1 \%)$, también se reducen notoriamente con la vacuna ${ }^{9}$. Lamentablemente, la efectividad protectora se desvanece con los años luego de la vacunación. El riesgo de complicaciones aumenta progresivamente luego de la segunda dosis de la vacuna respecto a la frecuencia observada durante los primeros dos años de inmunización y llega a un valor 30 veces superior en aquellos que recibieron su última dosis hace 24 años 9 .

Los antecedentes aportados indican que el brote de parotiditis viral en Chile desde el 2015 es probablemente explicado por la inmunización para esta enfermedad iniciada hace cerca de tres décadas en nuestro país. A pesar que el brote regional actual se concentra en población joven, también afecta a grupos etarios mayores, subrayando la gran amplitud del problema. La existencia de un gran número de casos, permite a su vez la expresión clínica de complicaciones infrecuentes como las comunicadas en este reporte. El análisis epidemiológico confirma que nuestros casos se dieron en el contexto de un brote regional, cuando la cifra de incidencia es suficiente para la expresión de una complicación infrecuente y que, además, afecta a pacientes adultos. De esta manera, la detección de casos de parotiditis viral con manifestaciones neurológicas parece actuar como un evento centinela de un fenómeno epidemiológico subyacente. Sólo fue posible obtener información reciente de la cobertura regional de vacunación para la segunda dosis a los seis años de edad, con valores de $87-89 \%$ entre los años 2013 y 2015 . Estas cifras son subóptimas ya que generan constantemente una fracción susceptible que se acumula progresivamente ${ }^{10}$.

La parotiditis viral es producida por un virus ARN con envoltura lipídica que se transmite por contacto, gotas o fómites con un período de incubación de 15 a 24 días $^{11,12}$. Tiene una transmisibilidad moderada a alta. La infección se adquiere por inoculación y replicación viral en la mucosa nasal y respiratoria superior. La alta afinidad por el epitelio glandular explica la inflamación parotídea y en menor frecuencia, la orquitis y pancreatitis. Durante la fase tardía de la incubación y los primeros días de la enfermedad se produce una viremia transitoria con diseminación a diferentes órganos como genitales, páncreas, sistema nervioso central (SNC), riñones, etc. El compromiso renal es casi universal y explica la viruria presente durante las primeras dos semanas de la enfermedad ${ }^{11}$.

El compromiso neurológico puede ocurrir en la forma de hipoacusia sensorio-neural transitoria (aproximadamente $4 \%$ ), meningitis (cerca de un $10 \%$ ) o encefalitis
( 1 cada 400 a 6.000 casos) y rara vez en otras formas como mielitis transversa, síndrome de Guillain Barré o ataxia cerebelosa $^{11,12}$. Los cuadros de meningitis o encefalitis suceden en los días siguientes al inicio del aumento glandular, tal como fue observado en nuestros dos pacientes. Sin embargo, cerca de la mitad del total de casos de meningitis por virus parotídeo, confirmados por serología o cultivo viral no tienen inflamación parotídea ${ }^{12}$. La meningitis se reconoce por la aparición posterior a la parotiditis, de cefalea, signos meníngeos y un LCR alterado, a veces con hipoglucorraquia marcada en un contexto de pleocitosis mononuclear, como fue también observado en nuestros pacientes ${ }^{11,12}$. La duración del compromiso meníngeo es de aproximadamente una semana, sin riesgo de mortalidad o secuelas. En contraste, los cuadros de encefalitis por esta causa, se asocian a la presencia de compromiso de conciencia, convulsiones o focalización neurológica y aunque en la mayoría de los casos es de curso benigno y sin secuelas, existe un riesgo de mortalidad asociada cercana a $2 \%{ }^{11,12}$. Creemos que el compromiso meníngeo en nuestros dos casos está debidamente respaldado por la presencia de fiebre, cefalea, signos meníngeos y un LCR alterado asociado a un cuadro precedente o paralelo de aumento parotídeo, con serología compatible y ascenso de la amilasemia.

El desarrollo de parotiditis viral durante el embarazo no representa un riesgo especial de aborto o patología fetal lo que implica que el enfoque diagnóstico y de manejo se concentra solo en la madre ${ }^{11}$. En un estudio observacional con mujeres que sufrieron parotiditis viral durante el embarazo se detectó una tasa de abortos de $6,6 \%$ para infecciones en el primer trimestre y $3,5 \%$ de partos prematuros, cifras no superiores a la población general. Además, en un subgrupo de 26 de 57 neonatos vivos con registro y estudio serológico, no se detectaron casos con infección prenatal por serología $\operatorname{IgM}^{13}$. Estos antecedentes permiten tranquilizar a la afectada en el caso de concurrencia de parotiditis y embarazo.

El diagnóstico de parotiditis viral es fácil en pacientes que se presentan con aumento glandular parotídeo durante brotes epidémicos o con sus complicaciones asociadas, las que aparecen pocos días después de la parotiditis, como está sucediendo actualmente en la región. El diagnóstico se puede corroborar con la detección de material genético viral por RPC en muestras de saliva, orina, LCR o sangre, aunque en este último caso por un período muy breve ${ }^{11}$. El estudio molecular puede realizarse en muestras de saliva, hasta aproximadamente nueve días de evolución, o en orina hasta 14 días del inicio de los síntomas. Se debe mencionar que no todos los casos con compromiso neurológico se asocian a detección viral en el SNC.

En contraste, en ausencia de brotes y con altas tasas poblacionales de cobertura de la vacuna, el diagnóstico etiológico de la parotiditis es más amplio e incluye al 
virus de Epstein Barr, parainfluenza 1 y 3, influenza A, coxsakie virus, adenovirus, parvovirus B19, virus de la coriomeningitis linfocítica, VIH e infecciones supuradas por deshidratación en adultos mayores o asociadas a sialolitiasis. La lista incluye también inflamación glandular secundaria al síndrome de Sjoegren ${ }^{11,12}$. En un estudio prospectivo infantil con casos esporádicos, el uso de la RPC permitió identificar al virus Epstein Barr como el agente más frecuente de parotiditis, secundado por herpesvirus 6 y en tercer lugar por el virus parotídeo ${ }^{14}$.

El estudio serológico de la parotiditis viral depende de si el paciente tiene una primoinfección, una reinfección luego de la infección natural o una infección postvacunación. En casos de primoinfección suele detectarse simultáneamente positividad para los anticuerpos IgM e $\mathrm{IgG}$, situación encontrada en nuestros dos $\operatorname{casos}^{15}$. Para casos con reinfección se ha descrito una seropositividad $\operatorname{IgM}$ (en aproximadamente 60\%) acompañada de un aumento de los valores IgG positivos basales durante el seguimiento. Sin embargo, el estudio serológico en personas previamente vacunadas ha revelado una muy baja sensibilidad para los anticuerpos $\operatorname{IgM}(<10 \%)^{15-17}$. Los antecedentes entregados sugieren que, en el contexto actual, es más útil el diagnóstico molecular que la caracterización serológica de los casos, enfoque aplicado en algunos centros universitarios y que, además, permite una tipificación viral ${ }^{18}$.

Debido a que la vacuna trívirica se incorporó en el Programa Nacional de Inmunizaciones el año 1990, la edad de nuestras pacientes ( mayores de 30 años) sugiere que ellas no recibieron la primera dosis al año de vida, pero que la pudieron haber recibido a los seis años de edad, según el esquema vigente. Las campañas periódicas desarrolladas por el Ministerio de Salud, para la prevención de rubéola congénita, se han efectuado con una vacuna bivalente sarampión-rubéola, sin el componente parotiditis, por lo que es poco probable que estas pacientes hayan recibido refuerzos para esta enfermedad. Así, no se puede establecer si estos eventos corresponden a casos de primoinfección, reinfección después de una infección primaria o casos en personas previamente vacunadas. Descartamos que los eventos de meningitis aséptica observados en estos dos casos, correspondan a fenómenos post-vacuna ya que estos se observan en los días siguientes a la vacunación.
Es posible que en el brote regional, los tres mecanismos estén actuando (primoinfección, reinfección o en personas vacunadas). La posibilidad de una primoinfección o de infecciones post-vacuna depende de la cobertura de vacunación en la población.

\section{Conclusiones}

Aunque infrecuentes, las complicaciones neurológicas asociadas a cuadros de parotiditis viral, pueden observarse especialmente en casos de brotes comunitarios. Estos aparecen pocos días después del aumento de volumen glandular y en el caso de meningitis, pueden ser sospechados por la presencia de cefalea intensa, fiebre, signos meníngeos y un LCR alterado con pleocitosis de predominio mononuclear. El diagnóstico serológico es complejo en poblaciones con altas cobertura de vacunación por la baja sensibilidad de los anticuerpos IgM. En contraste, la detección de material genético por RPC en muestras de saliva $\mathrm{u}$ orina tiene mayor utilidad. El pronóstico es favorable con resolución rápida de los síntomas. El brote actual de parotiditis viral en Chile hace posible esta etiología en casos de meningitis aséptica o encefalitis.

\section{Resumen}

Comunicamos dos casos de meningitis aséptica asociadas a parotiditis viral en mujeres de edad mediana, una de ellas embarazada. Ambas se presentaron pocos días después del aumento de volumen parotídeo, con cefalea, fiebre y signos meníngeos, pleocitosis de predominio mononuclear en el LCR y resultados negativos para otras causas. La parotiditis fue confirmada por serología IgG e IgM positiva. Las pacientes tuvieron una evolución favorable con desaparición total de sus síntomas. Ambos casos ocurrieron durante un brote regional de parotiditis. La meningitis aséptica es una complicación frecuente de las parotiditis. Su diagnóstico puede lograrse por el aumento de volumen glandular precedente, la pleocitosis de predominio mononuclear en el LCR y una serología IgM e IgG positiva o detección genómica por RPC en muestra urinaria o salival. Esta complicación es más probable que sea observada durante brotes de parotiditis viral. 


\section{Referencias bibliográficas}

1.- Zamir C S, Schroeder H, Shoob H, Abramson N, Zentner G. Characteristics of a large mumps outbreak: clinical severity, complications, and association with vaccination status of mumps outbreak cases. Hum Vaccin Immunother 2015; 11: 1413-7. DOI: 10.1080/21645515.2015.1021522.

2.- Barskey A E, Glasser J W, LeBaron C W. Mumps resurgences in the United States. A historical perspective of unexpected elements. Vaccine 2009; 27: 6186-95. DOI: 10.1016/j.vaccine.2009.06.109.

3.- Muhsen K, Aboudy Y, Mendelson E, Green M S, Cohen D. Prevalence of mumps antibodies in the Israeli population in relation to mumps vaccination policy and incidence of disease. Epidemiol Infect 2007; 136: 688-93.

4.- Arday D R, Kanjarpane D D, Kelley P W. Mumps in the US Army 1980-86: Should recruits be immunized? Am J Public Health 1989; 79: 471-4.

5.- Mossong J, Bonert C, Weicherding P, Opp M, Reichert P, Even J, et al. Mumps outbreak among the military in Luxembourg in 2008: epidemiology and evaluation of control measures. Euro Surveill 2009; 14. pii:19121.

6.- Cardemil C V, Dahl R M, James L, Wannemuehler K, Gary H E, Shah M, et al. Effectiveness of a third dose of MMR vaccine for mumps outbreak control. N Engl
J Med 2017; 377: 947-56. DOI: 10.1056/ NEJMoa1703309.

7.- Departamento de Epidemiología. Minsal Chile Boletin epidemiológico trimestral de parotiditis (CIE 10 B26). Semana Epidemiológica 1-39 (1 de enero a 30 de septiembre). Chile, 2017. Disponible en http://epi.minsal.cl/wpcontent/ uploads/2017/10/BET_PAROTIDITIS OCTUBRE_2017.pdf

8.- Patel L N, Arciuolo R J, Fu J, Giancotti F R, Zucker J R, Rakeman J L, et al. Mumps outbreak among a highly vaccinated university community-New York City, january-april 2014. Clin Infect Dis 2017; 64: 408-12. DOI: $10.1093 / \mathrm{cid} / \mathrm{ciw} 762$.

9.- Orlíková H, Malý M, Lexová P, Ŝebestová H, Limberková R, Jurzykowská L, et al. Protective effect of vaccination against mumps complications, Czech Republic, 2007-2012. BMC Public Health 2016; 16: 293.

10.- Departamento de Estadísticas e Información de Salud. Ministerio de Salud, Chile. Inmunizaciones. Disponible en: http://www. deis.cl/estadisticas-inmunizaciones/. Visitado el 08.11.2018.

11.- Hviid A, Rubin S, Muhlemann K. Mumps. Lancet 2008; 371:932-44.

12.- Litman N, Baum SG. Chapter 157: Mumps. Mandell GL, Bennett JE, Dolin R, editors. Mandell, Douglas and Bennett's Principles and Practice of Infectious Diseases, 7th ed. Philadelphia: Churchill Livingstone Elsevier; 2010. p 2201-6.

13.- Enders M, Rist B, Enders G. [Frequency of spontaneous abortion and premature birth after acute mumps infection in pregnancy]. Gynakol Geburtshilfl iche Rundsch 2005; 45: 39-43.

14.- Kang H J, Kim S H, Chung J K, Lee S W, Choi S B, Eom H E, et al. Viral etiology of sporadic cases of parotitis among children in Korea during 2013-2014. J Med Virol 2018; 90 : 61-6. DOI: $10.1002 / \mathrm{jmv} .24935$.

15.- Sakata R, Nagita A, Kidokoro M, Kato A, Ogino K. Virus genotypes and responses of serum-specific antibodies in children with primary mumps and mumps reinfection. Pediatr Res 2015; 78: 580-4. DOI: 10.1038/ pr.2015.141

16.- Maillet M, Bouvat E, Robert N, BaccardLongère $\mathrm{M}$, Morel-Baccard $\mathrm{C}$, Morand $\mathrm{P}$, et al. Mumps outbreak and laboratory diagnosis. J Clin Virol 2015; 62: 14-9. DOI: 10.1016/j. jev.2014.11.004

17.- Trotz-Williams L A, Mercer N J, Paphitis K, Walters J M, Wallace D, Kristjanson E, et al. Challenges in interpretation of diagnostic test results in a mumps outbreak in a highly vaccinated population. Clin Vaccine Immunol 2017; 24(2) pii: e00542-16. DOI: 10.1128/ CVI.00542-16.

18.- Le Corre N, Barría S, López T, MartínezValdebenito C, Contreras AM, Ferrés M. Parotiditis en Chile: caracterización clínica y molecular de dos casos en una población altamente inmunizada. Rev Chilena Infectol 2018; 35: 198-203. DOI: 10.4067/s071610182018000200198 